\title{
Massive pulmonary embolism in a patient with polysplenia syndrome and interrupted inferior vena cava with azygous continuation
}

\author{
Carmen K. M. Cheung ${ }^{1}$, Man Fai Law ${ }^{1}$, Ka Tak Wong ${ }^{2}$, Mark T. K. Tam¹, Kai Ming Chow ${ }^{1}$
}

${ }^{1}$ Department of Medicine and Therapeutics, Prince of Wales Hospital, Hong Kong ${ }^{2}$ Department of Radiology, Prince of Wales Hospital, Hong Kong

Submitted: 10 January 2017

Accepted: 12 June 2017

Arch Med Sci 2018; 14, 1: 251-253

DOI: https://doi.org/10.5114/aoms.2018.72247

Copyright $\odot 2017$ Termedia \& Banach

Interruption of the inferior vena cava (IVC) is a congenital anomaly. In individuals with this anomaly, venous drainage of the lower limbs is achieved through a compensatory dilated vena azygos system. These anomalies are rarely associated with venous thrombosis, especially in young patients. Patients with polysplenia typically have IVC interruption with azygous or hemiazygous continuation. We herein report a young patient who presented with massive pulmonary embolism and recurrent syncope and was later found to have interrupted IVC with azygous continuation and polysplenia syndrome, a condition that has rarely been reported in the literature previously. It highlights the importance of considering rare causes of pulmonary embolism in patients, particularly younger individuals in whom the classical risk factors are absent.

A 19-year-old Chinese secondary school student was admitted for recurrent episodes of syncope, preceded by shortness of breath. The syncope was not associated with limb twitching, or urinary or bowel incontinence. His syncope episodes are notably preceded by exercise including climbing upstairs and basketball game. He had a history of right inguinal hernia with surgical repair done in childhood. He had 10 siblings and they all enjoyed good health; there was no family history of venous thrombosis.

Physical examination of the cardiovascular and respiratory systems was unremarkable. There was no focal neurological deficit, but he had one episode of tonic convulsion after admission. Electroencephalography ruled out epileptiform discharges. Blood tests showed normal complete blood counts with a platelet count $173 \times 10^{9} /$ l. However, he had an elevated troponin T level of $59.4 \mathrm{ng} / \mathrm{l}$ (normal range $<14.0 \mathrm{ng} / \mathrm{l}$ ) and electrocardiography revealed marked right axis deviation with predominant $\mathrm{S}$ waves in limb lead I, and T wave inversion in limb lead III. Echocardiogram showed right ventricular dilatation with a D-shaped left ventricle, suggestive of right heart pressure overload. He then underwent computed tomography pulmonary angiography (CTPA), which revealed a massive occlusive pulmonary embolism in bilateral lower lobe pulmonary arteries (Figure $1 \mathrm{~A}$ ), and near occlusive pulmonary embolism in the rest of the segmental pulmonary arteries. The thrombus extended to the most distal part of the right and left main pulmonary arteries, but the main pulmonary trunk remained clear. He was treated with intravenous thrombolytic therapy (alteplase $100 \mathrm{mg}$ ), followed by subcutaneous low molecular weight heparin (enoxaparin $50 \mathrm{mg}$ twice daily according to

\author{
Corresponding author: \\ Man Fai Law \\ Department of Medicine \\ and Therapeutics \\ Prince of Wales Hospital \\ 852 Shatin \\ Hong Kong \\ Phone: 852-97763090 \\ E-mail: mflaw99@yahoo. \\ com.hk
}


body weight). An echocardiogram 4 days after the injection of tissue plasminogen activator showed a mildly dilated right ventricle but preserved right ventricular systolic function without residual tricuspid regurgitation. The patient remained stable after thrombolytic therapy. He was anticoagulated with rivaroxaban.

The patient underwent further work-up to investigate the underlying cause of the massive pulmonary embolism. Levels of all tumor markers, autoimmune markers and lupus anticoagulant were unremarkable. Gene-related thrombophilia such as factor $\mathrm{V}$ Leiden and prothrombin G20210A mutations were not tested because these are very rarely found in Chinese patients. A positron emission tomography-computed tomography (PET-CT) scan showed features suggestive of polysplenia syndrome with multiple small spleens (Figure 1 B). There were also multiple blood vessel abnormalities. The IVC drained directly into the azygous vein and into the superior vena cava. Furthermore, it did not go through the liver, and the left renal vein drained into the left sided hemiazygous vein while the right renal vein drained into the IVC (Fig- ures $1 \mathrm{C}, \mathrm{D})$. The hemiazygous vein drained into the azygous vein in the thorax. The pancreas was also short in length. The patient was continued on anticoagulation and remained well. At subsequent follow-up 1 year later, there was no evidence of recurrent pulmonary embolism.

The normal anatomy of the IVC consists of four main segments: hepatic, suprarenal, renal, and infrarenal [1]. When the right subcardinal vein fails to converge with the hepatic sinusoids, hepatic segment anomalies occur. Blood is then shunted from the suprasubcardinal anastomosis through the retrocrural azygous vein [2]. Azygous continuation of the IVC is defined as the absence of the hepatic segment of the IVC with azygous continuation [2]. This anomaly is a rare clinical condition and is a hallmark of polysplenia syndrome, a condition within the spectrum of heterotaxy or situs ambiguous syndromes, which includes polysplenia and asplenia.

Heterotaxy is defined as an abnormality where the internal thoraco-abdominal organs demonstrate abnormal arrangement across the left-right axis of the body. This broad term includes patients with a wide variety of very complex cardiac le-
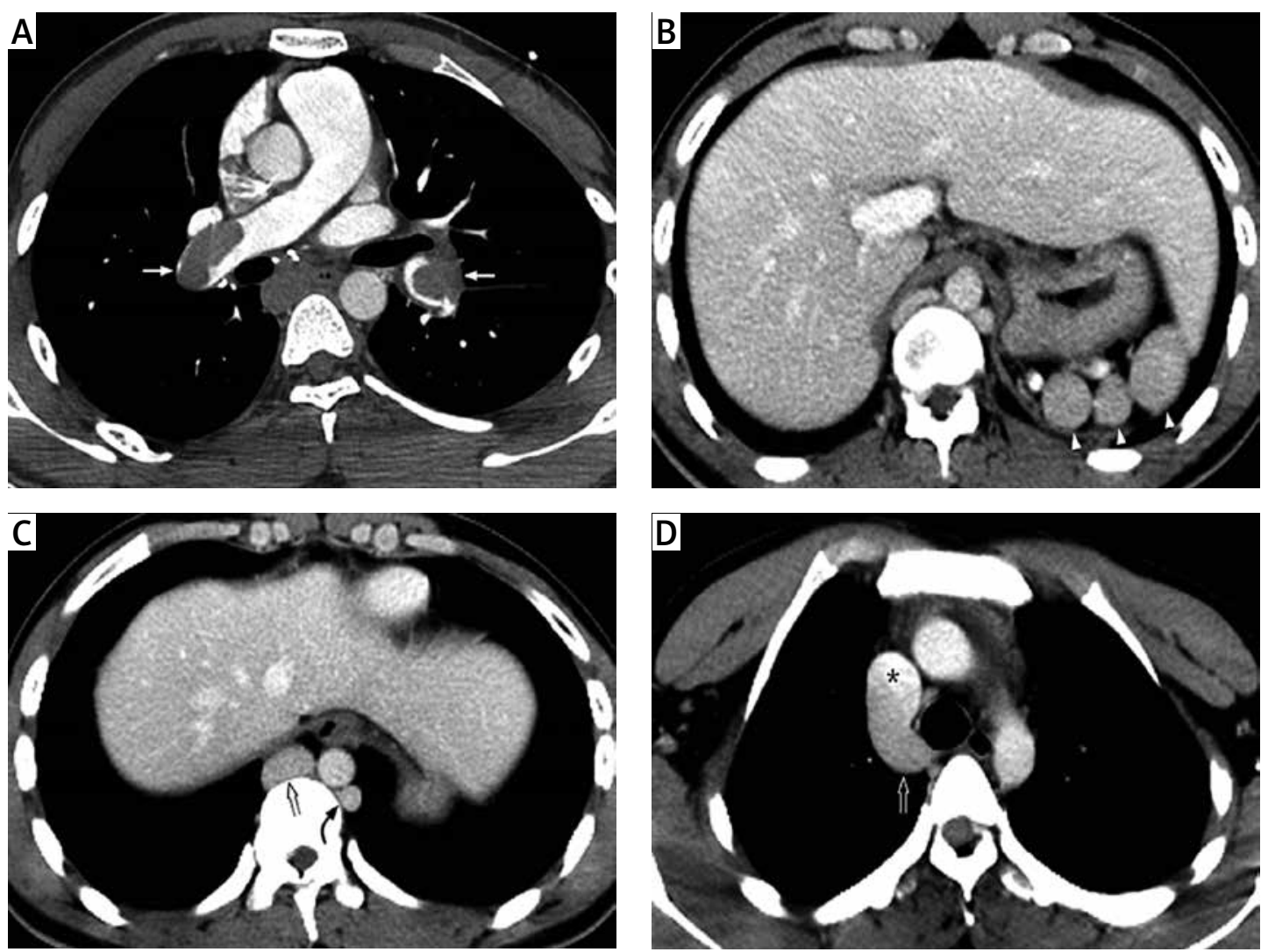

Figure 1. A - Computed tomography pulmonary angiography (CTPA) showed filling defects within right lower lobe and left lower lobe pulmonary arteries (arrows) suggestive of pulmonary embolism. B - Contrast enhanced computed tomography (CT) of the upper abdomen revealed multiple small spleens (arrowheads). $\mathbf{C}-\mathrm{The}$ hepatic segment of the inferior vena cava (IVC) was absent with IVC continuation into the dilated azygos vein (open arrow). The hemiazygos vein (curved arrow) was also dilated and received drainage from the left renal vein. D - Contrast enhanced CT of the upper mediastinum showed final drainage of the dilated azygos vein (open arrow) into the superior vena cava (asterisk) 
sions. The estimated prevalence is approximately 1 in 10,000 live births [3]. The outcomes of patients with heterotaxy are highly variable due to the wide spectrum of both cardiac and noncardiac anatomical anomalies.

The absence of the intrahepatic and other segments of the IVC represent an interruption of a right-sided structure. Venous return is restored by the azygous or hemi-azygous continuation into the superior vena cava, or less commonly into the intrahepatic veins [4]. The azygous vein originates from the posterior part of the IVC at the level of the renal veins. When azygous continuation of the IVC is present, blood from the viscera and lower extremities will return to the right atrium through the azygous vein.

Inferior vena cava anomalies are recognized as risk factors for deep vein thrombosis (DVT). Ruggeri et al. identified IVC anomalies in four of 75 patients at the first episode of DVT [5]. Another study showed that among 31 patients with iliofemoral DVT who were prospectively assessed by venography and magnetic resonance angiography, five anomalous IVCs were found [6]. An interrupted IVC may cause an increase in blood pressure in the lower extremity veins with insufficient collateral vessels. This results in venous stasis, which predisposes to DVT and pulmonary embolism. Pulmonary embolism in patients with interrupted IVC with azygous continuation has been rarely reported [7]. There are reports of patients with incidental findings of azygous continuation of the IVC with anomalous hepatic vein drainage or interrupted IVC with dilated azygous and hemiazygous veins $[8,9]$. These patients had increased risk of DVT and pulmonary embolism.

It should also be noted that despite being polysplenic, the spleen is usually considered to be hypofunctional [10]. Heterotaxy syndrome has been reported to be associated with thromboembolism related to thrombocytosis secondary to hypofunction of the spleen and congenital absence of the IVC $[11,12]$.

In conclusion, polysplenia syndrome and IVC abnormalities are rare congenital abnormalities associated with an increased risk of thromboembolism. The IVC anomalies should be considered as possible risk factors for patients with pulmonary embolism or deep vein thrombosis, especially in young patients.

\section{Conflict of interest}

The authors declare no conflict of interest.

\section{References}

1. Bass JE, Redwine MD, Kramer LA, Huynh PT, Harris JH Jr. Spectrum of congenital anomalies of the inferior vena cava: cross-sectional imaging findings. Radiographics 2000; 20: 639-52.

2. Ginaldi S, Chuang VP, Wallace S. Absence of hepatic segment of the inferior vena cava with azygous continuation. J Comput Assist Tomogr 1980; 4: 112-4.

3. Kim SJ. Heterotaxy syndrome. Korean Circ J 2011; 41: 227-32.

4. Pillai JB, Kpodonu J, Yu C, Borger MA Heterotaxy syndrome with azygous continuation-causing pseudo Budd-Chiari syndrome after cardiopulmonary bypass. Ann Thorac Surg 2006; 81: 1890-2.

5. Ruggeri M, Tosetto A, Castaman G, Rodeghiero F. Congenital absence of the inferior vena cava: a rare risk factor for idiopathic deep-vein thrombosis. Lancet 2001; 357: 441.

6. Bass JE, Redwine MD, Kramer LA, Harris JH Jr. Absence of the infrarenal inferior vena cava with preservation of the suprarenal segment as revealed by $C T$ and MR venography. AJR Am J Roentgenol 1999; 172: 1610-2.

7. Okur A, Intepe YS, Serin HI, Yıldırım U, Mavili E. Recurrent pulmonary embolism in an asthmatic patient who had interrupted inferior vena cava with azygous continuation. Turk Kardiyol Dern Ars 2014; 42: 277-80.

8. Guardado FJ, Byrd TM, Petersen WG Azygous continuation of the inferior vena cava with anomalous hepatic vein drainage. Am J Med Sci 2012; 343: 259-61.

9. Mehta AJ, Kate AH, Gupta N, Chhajed PN Interrupted inferior vena cava syndrome. J Assoc Physicians India 2012; 60: 48-50.

10. Lin AE, Ticho BS, Houde K, Westgate MN, Holmes LB. Heterotaxy: associated conditions and hospital-based prevalence in newborns. Genet Med 2000; 2: 157-72.

11. Kothari SS. Non-cardiac issues in patients with heterotaxy syndrome. Ann Pediatr Cardiol 2014; 7: 187-92.

12. Yamamura K, Joo K, Ohga S, et al. Thrombocytosis in asplenia syndrome with congenital heart disease: a previously unrecognized risk factor for thromboembolism. Int J Cardiol 2013; 167: 2259-63. 